\title{
Article
}

\section{A Bioecological Perspective on Talent Identification in Junior-Elite Soccer: A Pan-European Perspective}

Reeves, Matthew and Roberts, Simon J.

Available at http://clok.uclan.ac.uk/31012/

Reeves, Matthew ORCID: 0000-0002-3903-2910 and Roberts, Simon J. (2020) A Bioecological Perspective on Talent Identification in Junior-Elite Soccer: A Pan-European Perspective. Journal of Sports Sciences, 38 (11-12). pp. 12591268. ISSN 0264-0414

It is advisable to refer to the publisher's version if you intend to cite from the work. http://dx.doi.org/10.1080/02640414.2019.1702282

For more information about UCLan's research in this area go to http://www.uclan.ac.uk/researchgroups/ and search for <name of research Group>.

For information about Research generally at UCLan please go to http://www.uclan.ac.uk/research/

All outputs in CLoK are protected by Intellectual Property Rights law, including Copyright law. Copyright, IPR and Moral Rights for the works on this site are retained by the individual authors and/or other copyright owners. Terms and conditions for use of this material are defined in the policies page.

\section{CLoK}

Central Lancashire online Knowledge www.clok.uclan.ac.uk

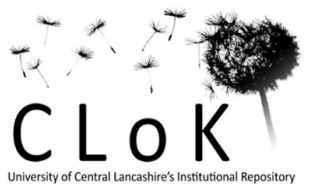


1 TITLE: A Bioecological Perspective on Talent Identification in Junior-Elite Soccer: A

2 Pan-European Perspective

3

4 Authors: Matthew J. Reeves ${ }^{1}$ and Simon J. Roberts ${ }^{2}$

5

$6{ }^{1}$ School of Sport \& Health Sciences, University of Central Lancashire, Preston, 7 Lancashire, PR1 2HE.

$8 \quad{ }^{2}$ School of Sport \& Exercise Sciences, Liverpool John Moores University, IM Marsh

9 Campus, Barkhill Road, Liverpool, L17 6BD.

10

11 Corresponding Author: Matthew J. Reeves

12 Email: mreeves4@uclan.ac.uk

13 Telephone: $+44(0) 1772893314$

14 ORCiD: 0000-0002-3903-2910 
TITLE: A Bioecological Perspective on Talent Identification in Junior-Elite Soccer: A

\section{Abstract}

Elite soccer clubs across Europe spend ever-increasing sums of money on 
Professional soccer clubs across Europe are spending ever-increasing sums of money on the transfer fees and salaries of world-class players. Consequently, increasing sums

40 are also being spent on academy level talent identification and development (TID)

41 processes and practices, which continue to become increasingly professionalised 42 (Larsen et al., 2013). Indeed, identifying and developing junior talent in soccer has 43 become a critical issue for clubs and national federations. It is, therefore, unsurprising 44 that the Union of European Football Associations (UEFA) and some national leagues 45 have launched 'localised' initiatives designed to promote their TID outcomes 46 (Richardson, et al., 2012); though recent findings suggest that home-grown players 47 have lower employment rates in their home country than players developed elsewhere (Poli, Ravenel, \& Besson, 2015; Poli, Ravenel, \& Besson, 2018). Whilst there have been a number of initiatives to develop and increase the number of home-grown players,

50 there appears to be wider issues affecting these developments. For example, evidence 51 suggests that the Premier League has the second lowest number of indigenous players 52 when compared to the other major European leagues (i.e. Bundesliga, Ligue 1, Serie A, 53 and La Liga) (Littlewood, Mullen, and Richardson, 2011). Whereas, Spain and Italy 54 are highlighted as having the largest percentage of indigenous players in their leagues, 55 suggesting that there are both cultural and philosophical conditions within those 56 countries that encourages players to remain in their native country (Richardson, Relvas $57 \&$ Littlewood, 2013). However, the most recent data suggest that the footballers' labour 58 market across Europe has become de-territorialized, evidenced by a decreased number 59 of club-trained players at their indigenous club, increased numbers of expatriate players, 60 and greater player mobility; these factors contribute toward difficulties for clubs 
61 adhering to league or federation requirements on home-grown talent numbers within their squads (Poli, Ravenel, \& Besson, 2018).

Identifying and developing elite soccer players is a time-consuming and complicated process (Baker et al., 2018) and it is no surprise that most professional soccer clubs have their own systems and structures for determining the level of complexity they are willing to accept as part of their TID strategy (Richardson, Relvas \& Littlewood, 2013). However, it is also important to recognise that 'identification' is only the first step (Larkin \& Reeves, 2018) in a long and winding talent development road (Baker, Wattie \& Schorer, 2019). Therefore, when discussing talent identification and/or selection, it is also important to recognise the integration of the talent development environment and how these mechanisms, processes, and decisions operate at a pragmatic and functional level (Collins, MacNamara \& Cruikshank, 2018; Ivarsson et al., 2015). However, we add a note of caution here, as it is not our intention to promote or extend the debate into what is talent in sport as this is adequately covered elsewhere (see Baker et al., 2019).

In this article, we provide a theoretical insight into the talent identification processes and development environments from some of Europe's most productive professional soccer academies. In terms of advancing best practice in the field of TID research, Urie Bronfenbrenner's $(1979,2005)$ bioecological model of human development acts a useful framework, as it can represent both the dimensions and 81 outcomes of the athletic environment and the roles and functions of the participants involved in the talent recruitment process. Although it must be noted, the working model applied in this paper does not fully correspond with Bronfenbrenner as it does not include the meso and exo levels. However, as Collins, MacNamara and Cruikshank (2018, p. 8) suggest, this still contributes a 'contextually situated perspective' to the 
talent research literature and provides a unique opportunity to examine TID from an applied ecological setting. Specifically, the holistic ecological approach (HEA) to talent in sport (i.e. Henriksen, Stambulova, \& Rossler, 2010a, 2010b, 2011) shifts the researcher emphasis away from the physical, perceptual-cognitive, technical, and tactical attributes of the individual player to the context of the environment where the player develops (i.e. the academy). This shift in focus is represented by two applied theoretical models (Henriksen, Stambulova \& Roessler, 2010). The first, which is termed the athletic talent development environment (ATDE), and is defined as a framework that comprises of the following:

“...a dynamic system comprising (a) an athlete's immediate surroundings at the microlevel where athletic and personal development take place, (b) the interrelations between these surroundings, (c) at the macrolevel, the larger context in which these surroundings are embedded, and (d) the organisational culture of the sports club or team, which is an integrative factor of the ATDE's effectiveness in helping young talented athletes develop into senior elite athletes" (Henriksen, 2010, p. 160).

Empirical evidence to support the applied architecture of the ADTE has previously been reported across individual sports such as kayaking (Henriksen, Stambulova \& Rossler, 2010), golf (Henriksen, Larsen \& Christensen, 2014) and track and field (Henriksen, Stambulova \& Rossler, 2010b). The ATDE has also explored the dynamics and interactions between players and coaches in team sports such as soccer, however, these have tended to be restricted to isolated case studies of professional soccer clubs in Scandinavia such as Denmark (Larsen et al., 2013) and Norway (Aalberg \& Saether, 2016). The second working model, the environment success factors (ESF), is grounded in organisational psychology (Schein, 1990) and emphasises 
111 the organisational culture of the environment. The ESF model comprises a set of 112 preconditions (i.e. human, material, financial), the process (i.e. training and formal 113 competition), the organisational culture (i.e. artefacts) and the team development, 114 which operates in tandem with the ADTE and acts as a framework to measure impact 115 and effectiveness (Henriksen et al., 2010). Features of successful ADTEs have 116 included: inclusive training environments; role models; emphasis on long-term 117 development rather than short-term success; a consistent and rationale organisational 118 culture; and the assimilation of sporting demands.

To our knowledge the ADTE and ESF have not been empirically examined 120 across recruitment systems and cultures other than Scandinavia. Furthermore, whilst 121 we understand that the ADTE and ESF were designed, initially, to provide holistic 122 descriptions of the talent development environment, we also believe this could be 123 adapted to offer a more detailed insight into the identification processes that exist within 124 this particular domain. We also agree with Collins et al. (2018) that previous TID 125 research has relied typically on singular methodologies, such as the retrospective recall 126 interviews, and despite the methodological limitations (i.e. self-report bias) associated 127 with this methodology it continues to permeate the TID literature. In view of these 128 shared concerns we believe that these two working models has much to offer in terms 129 of how socially constructed interview data can inform the current TID landscape in 130 junior-elite soccer. For instance, the interview guides designed by Henriksen et al. 131 (2010) gathered data that were captured from interviewees in their 'current' 132 organisational role (i.e. coaches, recruitment staff, etc.) and, therefore, may go some133 way to address the reliability issues associated with retrospective recall. The present 134 study also represents a response to Henriksen et al. (2011) who called for more research 135 of environments in which senior athletes continually achieve top level results. 
136 Therefore, the focus of this study was to explore how talent identification is framed

137 within the context of ADTE and operationalised within the ESF at some of the most 138 successful soccer academies in Europe. Specifically, the aims of the present study were:

139 (1) further our understanding of talent identification processes and mechanisms in 140 ATDEs in junior-elite soccer; and (2) examine the factors influencing its success in 141 developing junior-elite soccer players.

\section{Method}

\section{Situated context}

Across Europe, a professional soccer academy, defined as an elite performance development environment, is where potentially talented players are identified and

146 recruited with the aim of becoming professional players (Mills, Butt, Maynard and

147 Harwood, 2012; Larsen et al., 2013). For junior players (i.e. 8-16 years old) selected

148 for an academy, especially academies of elite professional clubs, these environments 149 offer some of the very best resources and training facilities (Ashworth \& Heyndels, 150 2007). The organisational structure of professional academies can vary, but will 151 typically include personnel such as head of academy/academy director, full-time 152 coaches, part-time assistant coaches, sports scientists, heads of recruitment, and full153 time and part-time talent scouts. See Relvas (2010) for a detailed analysis of the 154 organisational structures and working practices of European soccer academies.

155 Participants

Eleven heads of recruitment aged between 34 and 62 years old $(m 48.5, \pm 9.5$

157 years) participated in this study. To provide a balanced and geographically diverse 158 perspectives on junior-elite player environments (Mills et al., 2014), heads of 
recruitment from 11 professional clubs' academies around Europe agreed to participate in this study. Further, to include a depth and richness to the information required (Patton, 2002), it was necessary to recruit a sample that could be considered responsible for the identification of players that had progressed to the highest levels of performance within their respective professional leagues. Unlike other staff (i.e. coaches, sports scientists), it is not a pre-requisite for a head of recruitment to hold recognised qualifications. Therefore, given the specific nature of the inquiry, participants were recruited on the basis that participants were responsible for the day-to-day recruitment decisions across the academy. Each participant was male and had held their current position between 1.5 and 16 years $(m=8.5$ years, \pm 4.8 years $)$.

\section{Procedure}

In order to satisfy the stipulated inclusion criteria, the most productive academies, as determined by the Centre International d'Etude du Sport (CIES), were contacted (CIES, 2016). Academies identified in the CIES training club data were emailed ( $n=55)$, either directly to the named head of recruitment, or addressed for their attention via a club-based email address. There were 16 responses to the original request with a total of 11 heads of recruitment agreeing to participate. This represented a $20 \%$ response rate and included responses from professional clubs currently playing in the English Premier League $(n=3)$, French Ligue $1(n=3)$, German Bundesliga $(n=2)$, Italian Serie A $(n=1)$, and Spanish La Liga $(n=2)$. Institutional ethical approval was obtained, and informed assent and written consent was provided by all participants. Before starting the interview, participants were reminded of the purpose of the interview and informed they were free to withdraw at any time. There were not considered to be any language barriers as all participants were fluent in English and fully understood the questions that were posed. 
As this study formed part of a larger multidisciplinary talent identification project surrounding junior-elite soccer academy environments in the United Kingdom, 187 Western Europe, and Australia, rigour surrounding the pilot testing of interviews was 188 already established (i.e. Reeves et al., 2018). All interviews were conducted by the 189 principal researcher over a ten-month period, at dates and times convenient to the 190 participants and included venues such as the respective clubs' academy or stadium 191 offices. The interviews were semi-structured (Kvale \& Brinkman, 2009), which 192 enabled the researcher the opportunity to probe issues that were considered important 193 for the identification and development of talented youth soccer players. Similar to 194 Henriksen et al., (2010) the interview guide was divided into four sections. In the 195 introductory part, rapport-building questions (i.e. can you tell me a little about your 196 career journey and your current role) were asked. In the descriptive section, the 197 interview guide was informed by the ADTE and ESF models, and questions were asked 198 around the roles and function of the specific components of the identification processes 199 and the relationship between these mechanisms at the micro- and macro-levels. The 200 explanatory section included questions which probed the reasons behind the 201 environments success and factors that included preconditions, process, individual 202 development, and organisational culture. In the final part of the interview further 203 questions were posed that were designed to explore past traditions and future obstacles 204 for the environment. Interviews were digitally recorded and lasted between 52 minutes 205 and 114 minutes ( $m$ 87:53 \pm 20.10 minutes). The combined total of all interviews was $206 \sim 16$ hours. Following each interview critical discussion points were noted in theoretical 207 memos for use during analysis alongside fieldnotes (Rapley,2011). 
210 digitised to aid the analysis process. Transcribed material produced over 607 pages of

211 single-line spaced text ( 450,000 words). All transcribed data were imported into QSR

212 NVivo 11 and subjected to constant comparative analysis (Rubin \& Rubin, 1995). Data

213 collection and analysis occurred in parallel; with each subsequent interview the

214 generated categories were compared with existing ones to determine whether data

215 produced new discrete categories, became property of an existing category, or

216 represented a category with a higher level of abstraction (Parry, 2004). Analysis began

217 with open coding, whereby data were segmented into meaningful expressions before

218 being coded axially - reassembling the data that had been broken down during the open

219 coding process (Strauss \& Corbin, 1998). During the coding process, fieldnotes and

220 theoretical memos were shared amongst the research team, though there was no attempt

221 to seek consensus at this stage. All data treatment was performed by the principal

222 investigator, but final categories, interpretations and concepts of the ADTE and ESF

223 were shared until final agreement was reached. Field notes acted as aide memoires but

224 also provided context on interactions and process to support the credibility of date 225 interpretation (Koch, 2006). A final effort to ensure credibility was to share the final

226 proposed ATDE and ESF models with participants (Guba \& Lincoln, 1989). In total

227 nine participants responded to our request to review and comment. Aside from some 228 explanatory commentary, there was agreement as to the overall presentation and 229 representativeness of the model from all respondents. 
234 understand the talent identification processes and mechanisms in ATDEs in junior-elite

235 soccer, whilst also examining the factors influencing their success in developing elite 236 adult players. The investigation was concerned with the entirety of TID and, thus, 237 focussed on all ages groups as a departure for the describing of the empirical ATDE 238 model of these clubs (see Figure 1). Considering that all components of the environment 239 are interconnected and influence each other, the model demonstrates the most important 240 components and relationships alongside the structure of the environment (Larsen et al., 241 2013). The thickness of arrows demonstrates the closeness of the relationship, with the 242 most important relationships focussed around the Head of Recruitment.

243 Figure 1: The ATDE Empirical Model of European Talent Identification \& Recruitment !INSERT FIGURE 1 ABOUT HERE!

The micro-environments of the elite clubs were characterised by a range of 249 playing squads which range from pre-academy/development squads (i.e. players from $250 \mathrm{u} 8$ down who cannot be officially registered with the national federation by the club), 251 then U9s to U23s. Club-based support structures included coaches, assistant coaches, sports 253 scientists (including performance analysts and strength/conditioning coaches), medical 254 services (including physiotherapists, podiatrists, and a medical doctor). Here, staff were 255 qualified in a range of football qualifications (i.e. UEFA A licence and Pro-licence) and 
academic qualifications (i.e. BSc, MSc, and in some cases PhD). In addition, all of the clubs involved in the study had relationships with universities - sometimes local, sometimes at distance - and had some form of consultancy or support-role offered by those institutions. To close the research-practice divide these clubs were making best 260 use of research evidence to inform their talent identification and talent development 261 procedures and practices. For example, well established growth, maturation and 262 anthropometric research had permeated through the clubs' recruitment philosophy, and 263 there was consensus that predictability of talent based on physiology testing alone was 264 flawed. All the clubs adopted assessment protocols for measures of functional capacity 265 but combined these with soccer-specific tests for dribbling, ball control, shooting speed 266 and accuracy and perceptual-cognitive passing tests in congested areas in an attempt to 267 replicate the decision-making demands of competition. Furthermore, imposed 268 environmental constraints (i.e. a skewed distribution of selecting players born earlier in 269 a pre-defined age group comparative to those players born later due to an imposed cut270 off date), commonly referred to as relative age effects (RAEs; Haycraft, Kovalchik, 271 Pyne, Larkin, \& Robertson, 2018) which are known to affect a player's prospect of 272 becoming a full-time professional (Furley, Memmert, \& Weigelt, 2016) were 273 understood across all the clubs in this study. We documented pedagogical age group 274 modification strategies similar to those reported by Mann and van Ginneken (2016), 275 where talent scouts were provided with birthdates of players a priori and, in some 276 instances, the decimalisation of players' ages was provided on training vests during 277 real-time scouting assignments. Integrated age-ordered shirt numbering was also 278 mentioned as a pedagogic means by which academy coaches applied in situ age 279 appropriate coaching, thus ensuring technical and tactical skills were provided in 280 positive, supportive and developmentally appropriate environments. These findings are, 
281 therefore, at odds with recent qualitative investigations surrounding the implications of 282 RAEs in elite academy environments (Andronikos et al., 2016).

From a biological perspective, variations between chronological age and 284 biological maturation was also understood and, in some cases, estimates of 285 skeletal maturity were in place to measure and monitor players classified as late, 286 average or early maturity according to birth date quarter. One club mentioned the 287 adoption of bio-banding strategies following the recommendations of the 288 literature (Cumming et al. 2017), that is, adolescent soccer players were grouped 289 according to biological maturation bands given by percentage of predicted mature 290 stature that was attained by participants at a specific chronological age. Together 291 these findings suggest the academies are perhaps more 'educated' about the 292 nuances of talent than has been suggested previously. We recorded no evidence 293 that recruitment staff were mis-understanding anthropometric characteristics as 294 a beneficial variable for future performance, however, saying that, it was outside 295 the scope of this study to capture statistical date-of-birth data, maturational 296 indicators, or anthropometric measures, so we are unable to report as to whether 297 these well-established talent recruitment problems were mediated.

Pivotal to the working demands of this model across all these clubs is the 299 relationship between the head of recruitment, club-based support structures and other 300 recruitment staff, who were classified as full-time recruitment staff, local scouts, or at 301 distance scouts. Full time recruitment staff were an essential component of the TID 302 paradigm, mainly responsible for administrative components of talent identification (i.e. 303 liaising with scouts regarding games to attend), though these roles also included 304 attending games and observing potentially talented youngsters. 
Local grassroots clubs were largely held as critical components of the scouting and recruitment process. All participants indicated that local clubs and, thus, local players, was “...what it's all about...getting youngsters who know and probably support the club, playing for the first team if we can...they understand our history, our culture" (Participant ES2). Therefore, the relationships between academy staff (i.e.

311 scouts and recruitment) and local clubs was seen as being of paramount importance,

312 but also had a financial benefit as there were lower associated costs with these players 313 during their developmental period (Reeves et al., 2018).

\section{Micro-environment: non-athletic domain}

316 connections with club-based support structures. This was, in part, due to the link

317 between an education officer (or similar) who was employed by the club and acted as a 318 liaison between school and academy. Education was a critical characteristic for all 319 players involved with their respective academies, though the nature of this link varied 320 between clubs and even between individual players at the same club (Christensen \& 321 Sørensen, 2009). Participants highlighted how schools were often seen as useful sites 322 of inside knowledge of an individual players' behaviour, motivation, and capacity to 323 learn. This insight gathering was typically undertaken by full time recruitment staff, 324 including the head of recruitment.

\section{Macro-environment}

The macro environment comprised people and groups with whom the players

327 do not have regular (i.e. at least weekly) contact. In some instances, player contact was 
not identified at all (i.e. At Distance Scouts). Here, it was possible to see the head of recruitment as the cornerstone of communication. Similar to findings from Relvas et al.

330 (2010), structural differences were apparent between participating academies, with 331 reserve teams/under 23 teams positioned differently. For example, in England, two of 332 the under 23 squads were all positioned within the academy environment with 333 seemingly tangential contact with the first team, whilst one was embedded alongside 334 the first team. In all instances, the teams were located in the same physical environment 335 (i.e. a single site training ground), though separated by organisational and facility-based 336 barriers (Dowling et al., 2018).

\section{Director of Football}

The role of the director of football (DoF) is common amongst European football

339 clubs, albeit with slight variances on the title and their associated responsibilities

340 (Parnell et al., 2019). Indeed, the functions performed in this role varied between clubs

341 from a focus on first team recruitment activities to oversight of all club activities

342 including: first team, academy, sports science and medicine, amongst other things 343 (Parnell et al., 2019). This resulted in variance in the types of communication that study 344 participants had with the DoF, and a largely hierarchical structure became apparent. 345 However, regardless of the organisational structure, contact between academy players 346 and academy-level staff (i.e. head of academy recruitment) was infrequent, typically 347 once per week, unless there were pressing matters (i.e. registration/contractual issues).

\section{First Team}

The first team environment was considered the 'end goal' by participants: their job was summarised as "...identifying the best potential talent, bringing it to the club,

351 allowing it to be developed and hoping that it turns into a professional footballer" 
352 (Participant GR1). There was acknowledgement that the first team environment was

353 used symbolically to motivate and sell the club to potential youngsters looking to join.

354 However, the closeness to the first team environment was suggested to be mostly

355 relevant to the professional development phase within the academy (i.e. U17 upwards).

356 Indeed, there is a growth in the research focussing on phases of transition (e.g. Morris,

357 Tod \& Eubank, 2017), organisational transitions (e.g. Morris, Tod \& Oliver, 2015), and

358 stakeholder perceptions (e.g. Morris, Tod \& Oliver, 2016).

359 Professional Club (Globally)

Relationships between clubs tended to have a focus on first-team performance,

361 with academies focussed on players within the professional development phase of their

362 careers, mainly exploring the transfer or loan transfer of those players: "Most stuff tends

363 to focus on the first team, and relationships with other clubs is the same... but we have

364 to work on it, too. We have lads who need loans and permanent moves and so do those

365 clubs, so it helps if there is an existing relationship in place" (Participant UK3). There

366 was also acknowledgement of the need to be aware of players that might be of interest,

367 what might be considered more traditional recruitment practice, as one participant

368 explained, "We have good links with clubs around the world... we have to, you never

369 know who is going to get spotted and whether you're going to need to consider

370 them ...that's why you need breadth of coverage and why you need to build relationships

371 with clubs so you can easily get on the phone and discuss things" (Participant BE1).

372 There appeared a desire for academies to find the best young talent to develop in order

373 to save money later down the line (Reeves et al., 2018; Pruna, Tribaldos \& Bahdur,

374 2018) and relationships emerged as an important aspect of that (Gerke \& Wäsche,

375 2019). Indeed, contemporary studies, adopting a network perspective suggest that 
376 clubs' success in the transfer of players is strongly associated with their networks and 377 relationships (Liu et al., 2016).

At distance scouts

Academies, as well as first teams, operate a number of scouts at distance, 380 including nationally and internationally. These individuals were unlikely to have 381 regular contact with others at the academy, except for the head of recruitment or, 382 sometimes, recruitment staff. Depending on the size of the club, these scouts sometimes 383 also undertook duties for the first team environment, too. "...we have about a dozen 384 global scouts, some who just do academy-related work, and some who do academy and 385 first team...it depends on where they are [geographically], how well we know them and 386 what they produce...in some of the smaller places, for example Scandinavia, Joris 387 [pseudonym] does about 50:50, first team and academy...we've worked together for a 388 long time and I know I can trust him to get on and do very well and he only comes to 389 me if it's something important" (Participant ES1). Of note, here, was the emphasis on 390 trust between the head of recruitment and scouts working at distance; undoubtedly the 391 operating distance required trust that the work required would be undertaken and that 392 the quality of information would be sufficient to enable clubs to make decisions in a 393 timely manner. "Because of the climate we operate in, we have to try and be first to 394 know things: who's playing well, who's coming through, who's had injury issues, who 395 might be worth keeping an eye on, it's an information industry masked as a football 396 one [laughs]" (Participant UK2).

There have been a number of high-profile clubs that have broken rules regarding 398 'tapping up' players, in their own countries and abroad. For example, in 2017 Liverpool 399 FC were banned from signing academy players and fined $£ 100,000$ for 'tapping up' a 
player registered with another club (Hunter, 2017). Participants suggested that in a

401 period of increased scrutiny, it was important to ensure scouts, particularly those 402 operating at distance, were mindful of these issues, and did not engage in practices that 403 might undermine the club's credibility. "We do our best to make sure things are done 404 correctly and procedures are followed, but there are lots of moving parts in recruitment 405 and typically, lots of people involved from agents, players, parents and club 406 officials...all wanting to have their input and all having different discussions. It can be 407 a minefield at times" (Participant UK1).

\section{The ESF working model}

409 The ESF model (Figure 2) represents the factors influencing the success of

410 these 11 clubs in relation to the ADTE. Unlike previous iterations of this model from

411 different sports, we were unable to suitably distinguish between preconditions,

412 process, and organisational development and culture. Thus, these three components

413 overlap in order to demonstrate the strong congruence between them and the

414 inseparable nature of one from another.

415 Figure 2: The ESF Empirical Model of European Talent Identification \& Recruitment

!INSERT FIGURE 2 ABOUT HERE!

Preconditions

Financial resources offered a competitive advantage in the identification of 421 players. Specifically, finance was linked to the global breadth of coverage that a club 422 was able to achieve in their identification efforts. "We're lucky that the club takes global 
recruitment seriously...we have invested in this recently...I think because it is always

424 getting harder to do what we do" (Participant IT1). A club's ability to identify and

425 recruit players internationally was considered closely linked to their international image, 426 as was being able to establish satellite academies. "Part of being at a club like this is 427 realising that we are a global brand and we need to operate like one...having 428 academies in other countries is just part of this" (Participant DE3). Importantly, a 429 club's history, identity and the expectations of club leaders and fans alike, was a key 430 precondition and manifest in the clubs overall playing philosophy and, thus, recruitment 431 practices (Nesti \& Sulley, 2014).

432 Process

A critical component of identifying talented youngsters, was considering 434 whether they would be suitable for the clubs playing philosophy. "We have to be sure 435 what and who we're getting involved with...that's why we spend so much time getting 436 to know as much about a player as we can. Their attitude, their resilience, and 437 everything else going on in their heads...will they be able to work with us? Are they 438 willing to listen and to learn? They are the basic questions we have to answer." 439 Recruitment to a club's academy was typically at the under nine age group, though all 440 participants indicated that they ran a range of 'pre-academy' opportunities, though the 441 exact operation of these varied from club-to-club. These pre academies enabled clubs 442 to offer their coaching curriculum to youngsters who might have the potential to join 443 the academy proper at the appropriate age. This was noted as an opportunity for scouts 444 and recruitment staff to begin building and developing relationships with potential 445 future players and their parents. Such relationships with parents can be seen as crucial, 446 with the needs and identities of parents shifting and mutating as their child becomes 447 further enveloped in junior-elite football (Clarke \& Harwood, 2014). However, scouts 
and recruitment staff were also expected to place significant emphasis on building and

449 developing relationships with other stakeholders, including other scouts, grassroots

450 clubs and leagues, regional squads, coaches, and administrators. In essence, no stone

451 was expected to be left unturned in the quest for unearthing potential talent.

Cultural Paradigm

All clubs' facilities were utilised to position the club positively. For example, walls were frequently adorned with large photographs of successful academy teams, academy graduates, and positive written statements. There was also a significant use of club colours on walls and emphasis of the club's philosophy and values around the academy buildings, including reception, waiting areas, gyms, and changing rooms. Such artefacts have been suggested to manifest into the currency and discourse of the club. However, previous work in the UK (Reeves et al., 2018) has suggested that such artefacts do not always manifest in such positive ways, emphasising that culture cannot

461 be built through words and images alone. "It's important for the boys that messages are 462 consistent, probably for some staff, too [laughs]...it's also important that they know 463 and are reminded what our goal is. The first-team wall [an artefact, listing all players 464 who have passed from the academy to play for the first team] is where it is specifically, 465 so every boy has to see it every time they come into the building... a constant reminder 466 of why they're here - to become a professional footballer" (Participant DE1).

467 It was particularly important for communication pathways to be clear, open, and honest. 468 This, it was suggested, was not related to just scouting and recruitment, but to all club 469 departments. Indeed, due to the fast-paced, fluid, and value entrenched nature of 470 football clubs (Ogbonna \& Harris, 2014), culture is, arguably, of greater importance 471 here than in other organisational environments. Wanting to be the best referred to being 
the best scouts and recruiters possible and wanting to be part of a club that was

473 acknowledged for producing players. "...we like to think that we operate, at all times,

474 clearly and honestly with each other, no matter who it is... it's part of what we are about

475 and helps us to work as well as we can do and achieve the best" (Participant FR1).

476 Continually being aware of the requirements and expectations of the club was an 477 organisational need and cultural norm, but also veered toward being an environmental 478 deliverable. For example, by being sensitive to the requirements and expectations of 479 the club automatically generates an outcome, though it is not necessarily tangible. "Part 480 of being honest with people is setting out exactly what their role is, how we would like 481 them to perform it, what we expect from them - whether it's formally reported or 482 verbally communicated back - that's crucial to my guys knowing what we need, 483 knowing what the level is we're expecting boys to be at...it's all connected, they have 484 to know our successes to be able to sell the club to others, but they've also got to be 485 sure someone they're putting forward is on that level” (Participant UK3).

Individual Development

Working in football recruitment has, historically, been based on gut feelings, an expert eye, and numerous opinions (Reeves et al., 2018; Day, 2011; Christensen, 2009).Though there have been recent attempts by national federations to develop the 490 profession and provide educational development opportunities (Levett, 2018). Whilst 491 there have been limited formal opportunities for scouts and recruitment staff to develop 492 professionally, the norm has been internal professional development (Reeves et al., 493 2018) and an expectation to reflect on their own practice, whether formally or 494 informally. "We have meetings every year, but it's difficult to get them all [scouts] here 495 at the same time...especially international scouts, we usually have to just talk things 496 through with them on the phone" (Participant FR3). 
The often-cited single goal of developing players for the first team (Littlewood,

499 Mullen \& Richardson, 2011) appeared to no longer be the sole focus of clubs and 500 academies. Whilst that remained a priority, clubs indicated how they now considered 501 different opportunities for players in their development environments. “...Take this kid, 502 for example [pointing out of an office window overlooking a training session taking 503 place outside], he's got good potential, he's 14 [years old], athletic, good family 504 background, does well at school...but he's not likely to play in our first team...we'll 505 keep hold of him for as long as its right to do so for us and him, and he'll probably go 506 on to have a career in the game somewhere, but it's not likely to be here. Obviously, I can't say a 100\% that'll be the case, things might suddenly click and he's exactly right 508 for us, but it's more likely when he gets up to the 18 s he'll get a deal and be sent on 509 loan or we'll look for a more permeant move for him" (Participant UK2). This effectively shifts the traditional paradigm of football recruitment. Indeed,

511 such approaches have a dual purpose: Firstly, they serve to position the club favourably 512 amongst stakeholders (i.e. players and parents). By keeping younger players in the 513 development system for a longer period, they 'keep the dream alive' for youngsters, 514 with a view to providing their 'career in the game', albeit not necessarily with that club. 515 It also allows the club to demonstrate and emphasise their capacity for player 516 development; even if a players' endpoint is not with that club, they can legitimately 517 claim they have developed a youngster that has become a professional player. Second, 518 it provides an opportunity for a club to retain a player's registration, but for the player 519 to go on loan in order to further develop, or to attain a permeant transfer. In both 520 scenarios the parent-club may benefit in multiple ways. For example, the parent-club 521 are able to keep-hold of a player's registration and let others take responsibility for their 
development; they are able to reduce their overall wage bill by having another club pay

523 some or all of a player's salary whilst they are on loan; a permeant transfer might be

524 arranged for the player due to the loan and, thus, the club benefits from a transfer fee,

525 but might also benefit over a longer period through contractual agreements (i.e. sell-on

526 and appearance clauses) that continue to provide an income after the player has left the

527 club. However, such scenarios would appear to favour those clubs with a strong

528 financial position from which to start (see preconditions), as higher numbers of players

529 has increased costs in salaries, equipment, support staff, etc., and loan deals are not

530 guaranteed, meaning players may be let go (i.e. made redundant) if a loan or permanent

531 deal cannot be achieved.

\section{STRENGTHS \& LIMITATIONS}

This study contains several strengths and limitations. This is the first study, to

534 our knowledge, that has attempted to apply the ATDE and ESF framework outside of

535 Scandinavia. It is also the first attempt to integrate multiple environments into one

536 analysis as well as apply the generic framework to talent identification as opposed to

537 talent development. However, caution must be applied when considering the findings

538 of this study, as the participants and their respective clubs comprised 11 of the most

539 productive academies in Europe. As such, our study does not highlight localised issues,

540 or cultural differences that may be present in different countries, leagues, and clubs.

541 The findings cannot be unconditionally incorporated into other contexts or sports.

\section{CONCLUSION}

Professional soccer clubs are notoriously secretive about their talent

544 identification, recruitment, and development procedures and access for researchers to

545 these environments can be a challenge (Roderick, 2006). Using a holistic ecological 
546 framework this study examined the talent identification environments of some of the 547 most productive soccer academies in Europe. Findings suggest that there are several 548 key factors that are influential in the identification of talented young players within 549 these clubs including the breadth of coverage at local, regional, national, and 550 international level. This study provides support for the use of ATDE and ESF as a

551 framework for junior-elite football environments to evaluate their talent identification 552 environment and structures. Findings indicate a shift from recruitment to develop 553 players for a clubs' first team, to a multi-faceted talent identification and recruitment 554 process that seeks players who might not quite make the first team, but still retain some 555 value by being loaned or sold for profit. Future studies might consider the interplay 556 between specific aspects identified in this study and to what degree each influences the 557 other. 
559 Aalberg, R. R., \& Sæther, S. A. (2016). The Talent Development Environment in a $560 \quad$ Norwegian top-level football club. Sport Science Review, 25(3-4), 159-182. $561 \quad$ https://doi.org/10.1515/ssr-2016-0009

562 Andronikos, G., Elumaro, A. I., Westbury, T., \& Martindale, R. J. J. (2016). Relative 563 age effect: implications for effective practice. Journal of Sports Sciences, 34(12), 1124-1131. https://doi.org/10.1080/02640414.2015.1093647

565

566

567

568

569

570

571

572

573

574

575

576

577

Ashworth, J., \& Heyndels, B. (2007). Selection Bias and Peer Effects in Team Sports. Journal of Sports Economics, 8(4), 355-377. https://doi.org/10.1177/1527002506287695

Baker, J., Schorer, J., \& Wattie, N. (2018). Compromising Talent: Issues in Identifying and Selecting Talent in Sport. Quest, 70(1), 48-63. https://doi.org/10.1080/00336297.2017.1333438

Baker, J., Wattie, N., \& Schorer, J. (2019). A proposed conceptualization of talent in sport: The first step in a long and winding road. Psychology of Sport and Exercise, 43, 27-33. https://doi.org/10.1016/j.psychsport.2018.12.016

Bronfenbrenner, U. (2005). Making human beings human: Bioecological perspectives on human development. Thousand Oaks, CA: Sage Publications.

Bronfenbrenner, U. (1979). The Ecology of Human Development: Experiments by Nature and Design. Cambridge, MA: Harvard University Press. 
578 Christensen, M. K. (2009). "An eye for talent": Talent identification and the "practical sense" of top-level soccer coaches. Sociology of Sport, 26(3), 365-382.

580 Christensen, M. K., \& Sørensen, J. K. (2009). Sport or school? Dreams and dilemmas 581 for talented young Danish football players. European Physical Education Review, 15(1), 115-133. https://doi.org/10.1177/1356336X09105214.

CIES Football Observatory. (2016). Training Clubs: Real Madrid and Ajax head the rankings, Barcelona downgrades. Neuchâtel. Retrieved from http://www.football-observatory.com/IMG/sites/b5wp/2016/163/en/

Clarke, N. J., \& Harwood, C. G. (2014). Parenting experiences in elite youth football: A phenomenological study. Psychology of Sport and Exercise, 15(5), 528-537. https://doi.org/10.1016/j.psychsport.2014.05.004

Collins, D., MacNamara, Á., \& Cruickshank, A. (2018). Research and Practice in Talent Identification and Development—Some Thoughts on the State of Play. Journal of Applied Sport Psychology. https://doi.org/10.1080/10413200.2018.1475430

Collins, D. J., Macnamara, A., \& McCarthy, N. (2016). Putting the Bumps in the Rocky Road: Optimizing the Pathway to Excellence. Frontiers in Psychology, 7. https://doi.org/10.3389/fpsyg.2016.01482 https://doi.org/10.1519/SSC.0000000000000281 
Day, D. (2011). Craft Coaching and the 'Discerning Eye' of the Coach. International Journal of Sports Science \& Coaching, 6(1).

Dowling, C., Reeves, M. J., Littlewood, M. A., Nesti, M., \& Richardson, D. (2018). Developing individuals whilst managing teams: perspectives of under 21 coaches within English Premier League football. Soccer \& Society, 19(8), 1135-1150. https://doi.org/10.1080/14660970.2018.1432381

Furley, P., Memmert, D., \& Weigelt, M. (2016). "How Much is that Player in the Window? The One with the Early Birthday?" Relative Age Influences the Value of the Best Soccer Players, but Not the Best Businesspeople. Frontiers in Psychology, 7. https://doi.org/10.3389/fpsyg.2016.00084

Gerke, A., \& Wäsche, H. (2019). Football, networks, and relationships. In C. A. Simon Chadwick, Daniel Parnell, Paul Widdop (Ed.), Routledge Handbook of Football Business and Management (pp. 273-281). London: Routledge. https://doi.org/10.4324/9781351262804

Guba, E., \& Lincoln, Y. (1989). Fourth generation evaluation. London: Sage Publications.

Henriksen, K., Stambulova, N., \& Roessler, K. K. (2010). Successful talent development in track and field: considering the role of environment. Scandinavian Journal of Medicine \& Science in Sports, 20, 122-132. https://doi.org/10.1111/j.1600-0838.2010.01187.x

Henriksen, K., Larsen, C. H., \& Christensen, M. K. (2014). Looking at success from its opposite pole: The case of a talent development golf environment in 
623 Henriksen, K., Stambulova, N., \& Roessler, K. K. (2010). Holistic approach to athletic talent development environments: A successful sailing milieu.

626 Psychology of Sport and Exercise, 11(3), 212-222. https://doi.org/10.1016/j.psychsport.2009.10.005

Henriksen, K., Stambulova, N., \& Roessler, K. K. (2011). Riding the Wave of an Expert: A Successful Talent Development Environment in Kayaking. The Sport Psychologist, 25(3), 341-362. https://doi.org/10.1123/tsp.25.3.341

Hunter, A. (2017, April). Liverpool banned from signing academy players and fined $£ 100,000$. The Guardian. Retrieved from https://www.theguardian.com/football/2017/apr/05/liverpool-banned-signingacademy-players-fined-stoke

Ivarsson, A., Stenling, A., Fallby, J., Johnson, U., Borg, E., \& Johansson, G. (2015). The predictive ability of the talent development environment on youth elite football players' well-being: A person-centered approach. Psychology of Sport and Exercise, 16(1), 15-23. https://doi.org/10.1016/j.psychsport.2014.09.006

Khamis, H. J., \& Roche, A. F. (1994). Predicting adult stature without using skeletal age: The Khamis-Roche method. Pediatrics, 94(4), 504-507.

Koch, T. (2006). Establishing rigour in qualitative research: the decision trail. Journal of Advanced Nursing, 53(1), 91-100. https://doi.org/10.1111/j.13652648.2006.03681.x 
643 Kvale, S., \& Brinkmann, S. (2009). InterViews: Learning the craft of qualitative

644 research interviewing (2nd ed.). Thousand Oaks, CA: Sage Publications.

645 Larsen, C. H., Alfermann, D., Henriksen, K., \& Christensen, M. K. (2013). Successful 646 talent development in soccer: The characteristics of the environment. Sport,

$647 \quad$ Exercise, and Performance Psychology, 2(3), 190-206.

648 https://doi.org/10.1037/a0031958

649 Levett, N. (2018). Foreword: talent identification in English junior-elite football.

$650 \quad$ Soccer \& Society, 19(8), 1079-1080.

$651 \quad$ https://doi.org/10.1080/14660970.2018.1432387

652 Littlewood, M., Mullen, C., \& Richardson, D. (2011). Football labour migration: an 653 examination of the player recruitment strategies of the 'big five' European 654 football leagues 2004-5 to 2008-9. Soccer \& Society, 12(6), 788-805. 655 https://doi.org/10.1080/14660970.2011.609680

656 Liu, X. F., Liu, Y.-L., Lu, X.-H., Wang, Q.-X., \& Wang, T.-X. (2016). The Anatomy 657 of the Global Football Player Transfer Network: Club Functionalities versus $658 \quad$ Network Properties. PLOS ONE, 11(6). 659 https://doi.org/10.1371/journal.pone.0156504

660 Mann, D. L., \& van Ginneken, P. J. M. A. (2016). Age-ordered shirt numbering 661 662 reduces the selection bias associated with the relative age effect. Journal of Sports Sciences, iFirst. https://doi.org/10.1080/02640414.2016.1189588

663 Mills, A., Butt, J., Maynard, I., \& Harwood, C. (2014). Examining the Development 664 Environments of Elite English Football Academies: The Players' Perspective. 
Mills, A., Butt, J., Maynard, I., \& Harwood, C. (2012). Identifying factors perceived to influence the development of elite youth football academy players. Journal of Sports Sciences, 30(15), 1593-1604.

670 https://doi.org/10.1080/02640414.2012.710753

671 Nesti, M., \& Sulley, C. (2014). Youth Development in Football: Lessons from the World's Best Academies. Oxon: Routledge.

Ogbonna, E., \& Harris, L. C. (2015). Subcultural tensions in managing organisational 674 culture: a study of an English Premier League football organisation. Human Resource Management Journal, 25(2), 217-232. https://doi.org/10.1111/1748-

Parnell, D., Groom, R., Widdop, P., \& Ward, S. (2019). The sporting director: Exploring current practice and challenges within elite football. In S. Chadwick, Football Business and Management. Abingdon, Oxon: Routledge.

Parry, K. W. (2004). Constant Comparison. In M. S. Lewis-Beck, A. Bryman, \& T. F. 682 683 684 Liao (Eds.), The SAGE Encyclopaedia of Social Science Research Methods. Thousand Oaks, California: Sage Publications, Inc. https://doi.org/10.4135/9781412950589.n161 Sage. 
Poli, R., Ravenel, L., \& Besson, R. (2018). Ten years of demographic analysis of the football players' labour market in Europe. Neuchâtel. Retrieved from http://www.football-observatory.com/IMG/sites/mr/mr39/en/

Poli, R., Ravenel, L., \& Besson, R. (2015). Youth training in European football: a comparative analysis. CIES Football Observatory Weekly Post. Neuchâtel. Retrieved from http://www.football-observatory.com/IMG/sites/mr/mr09/en/

Pruna, R., Miñarro Tribaldos, L., \& Bahdur, K. (2018). Player talent identification and development in football. Apunts. Medicina de l'Esport, 53(198), 43-46. https://doi.org/10.1016/j.apunts.2018.02.002

Rapley, T. (2011). Some pragmatics of qualitative data analysis. In D. Silverman (Ed.), Qualitative Research (3rd ed., pp. 273-290). London: Sage.

Reeves, M. J., Roberts, S. J., McRobert, A. P., \& Littlewood, M. A. (2018). Factors affecting the identification of talented junior-elite footballers: a case study. Soccer \& Society, 19(8), 1106-1121. https://doi.org/10.1080/14660970.2018.1432383

Relvas, H., Littlewood, M., Nesti, M., Gilbourne, D., \& Richardson, D. (2010). Organizational Structures and Working Practices in Elite European Professional Football Clubs: Understanding the Relationship between Youth and Professional Domains. European Sport Management Quarterly, 10(2), 165-187. https://doi.org/10.1080/16184740903559891

Richardson, D., Relvas, H., \& Littlewood, M. (2013). Sociological and cultural influences on player development. In A. M. Williams (Ed.), Science and Soccer: 

Routledge.

711 Richardson, D., Littlewood, M., Nesti, M., \& Benstead, L. (2012). An examination of the migratory transition of elite young European soccer players to the English Premier League. Journal of Sports Sciences, 30(15), 1605-1618.

714 https://doi.org/10.1080/02640414.2012.733017

715 Rubin, H. J., \& Rubin, I. S. (1995). Qualitative interviewing: The art of hearing data. 716 London: Sage.

717 Schein, E. H. (1990). Organizational culture. American Psychologist, 45(2), 109-119. https://doi.org/10.1037/0003-066X.45.2.109

719 Strauss, A., \& Corbin, J. M. (1998). Basics of qualitative research: Techniques and 720 procedures for developing grounded theory (2nd ed.). London: Sage.

721 Wattie, N., Schorer, J., \& Baker, J. (2015). The Relative Age Effect in Sport: A Developmental Systems Model. Sports Medicine, 45(1), 83-94.

723 https://doi.org/10.1007/s40279-014-0248-9 